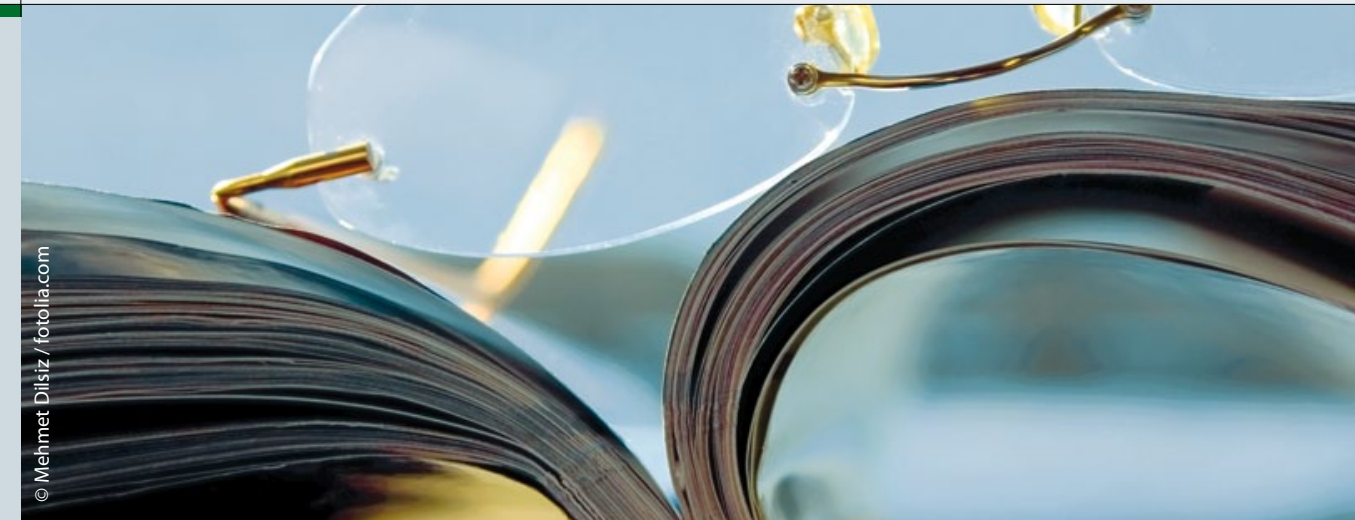

\section{Mit Kreuzblütlern gegen Prostatakarzinom?}

\section{Unzählige Studien haben bereits den Wert etwa von Kreuzblütlern wie Brokkoli, Romanesco oder Blumenkohl gegen das Fortschreiten des Prostatakarzinoms gepriesen. Doch die meisten fanden an Zellkulturen oder Tieren statt. Nun liegt tatsächlich eine prospektive Studie an Männern zum Thema vor.}

G emüse allgemein, Gemüse aus der Familie der Kreuzblütler wie Blumenkohl, Romanesco und Brokkoli oder das in Tomatensoße enthaltene Lycopin - sie alle wurden schon damit in Zusammenhang gebracht, das Risiko für einen Progress des Prostatakarzinoms zu senken. Das geht vor allem auf Labordaten und auf Tierversuche zurück. Doch für den Menschen gibt es nur sehr begrenzt aussagekräftige Daten. Wie meist in er- nährungswissenschaftlichen Fragestellungen sind prospektive Daten in besonderem Maße Mangelware. Aber allein sie gelten als verlässlich.

In der vorliegenden Studie wurde prospektiv untersucht, ob Männer mit einer Prostatakrebsdiagnose, die besonders viel des genannten Gemüses essen, ein geringeres Risiko für ein Fortschreiten ihrer Erkrankung haben als andere Männer. Es handelte sich allerdings nicht um eine

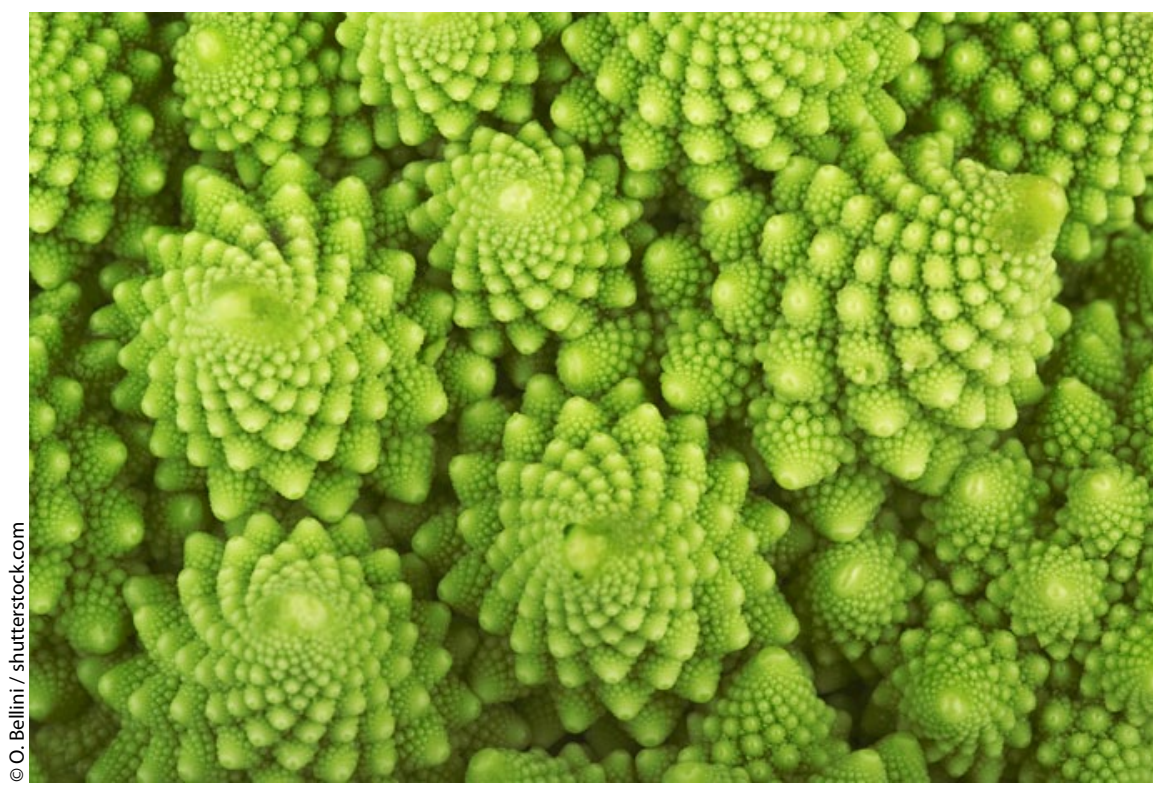

Einziges Gemüse, das hemmend auf das Prostatakarzinomwachstum zu wirken scheint: Kreuzblütler wie Romanesco
Interventionsstudie; die Probanden wurden nur nach ihrem Gemüsekonsum befragt. Dabei wurden nicht nur die Verzehrmengen der genannten Gemüse erforscht, sondern auch, wie viel Obst oder einzelne Früchtegruppen wie Beeren, Äpfel und Birnen oder Fruchtsäfte die Männer aßen beziehungsweise tranken.

1.560 Probanden wurden in die Studie aufgenommen; bei allen lagen zum Zeitpunkt der Diagnose noch keine Metastasen vor. In 3.171 Personenjahren kam es zu 134 Progressen. Die Männer wurden nach der Verzehrmenge an Kreuzblütlern in vier Gruppen eingeteilt. Die Männer mit dem größten Verzehr hatten ein statistisch signifikant geringeres Risiko für eine Progression im Vergleich zu den Männern in der niedrigsten Quartile: Das Risiko war um 59\% gesenkt; der Risikoquotient lag bei 0,41 . Kein anderes Gemüse und keine Frucht hatte dagegen einen Einfluss auf die Krebsprogression - auch Tomatensoße nicht.

Fazit: Der Verzehr der Gemüse aus der Familie der Kreuzblütler mag tatsächlich das Risiko für ein Fortschreiten eines zum Zeitpunkt der Diagnose noch nicht metastasierten Prostatakarzinoms mindern. Die Autoren warnen aber selbst davor, die Ergebnisse der Studie allzu sehr in Ernährungsratschläge einfließen zu lassen. Denn für eine Fragebogen-basierte Ernährungsstudie ist die Zahl der Probanden zu klein, um harte Aussagen zu treffen.

Christina Berndt

Richman EL et al. Vegetable and fruit intake after diagnosis and risk of prostate cancer progression. Int J Cancer 2012; 131: 201-10 